3. Barker RH Jr, Suebsaeng L, Roney W. Specific DNA probe for the diagnosis of $P$. falciparium malaria. Science 1986; 231: 1434-1436

4. Dulbecco R. A turning point in cancer research: Sequencing the human genome. Science 1986; 231: 1055-1056

5. Kolata G. Genetic screening raises questions for employees and insurers. Science 1986; $232: 317-319$

6. Weatherail DJ. The new genetics in clinical practice. 2nd Edition, Oxford University Press 1986; 206

7. Terasaki PI, Tiwari JL. HLA and disease associations. Springer-Verlag, 1985

8. Brattsten LB, Holoke CW Jr, Leeper JR, Raffa KF. Insecticide resistance: challenge to pest management and basic research. Science 1986; $231: 1255-1260$

9. Fox $\mathbf{C H}$, Cottler-Fox M. AIDS in the human brain. Nature $1986 ; 319: 8$

\title{
GENETIC PREDISPOSITION TO PHENYTOIN-INDUCED BIRTH DEFECTS
}

To find out whether arene oxide metabolites of phenytoin and a genetic defect in arene oxide detoxification contribute to susceptibility to phenytoin-induced birth defects, lymphocytes from 24 children exposed to phenytoin throughout gestation and from their families were challenged in a blind protocol with phenytoin metabolites generated by a murine hepatic microsomal drug metabolising system. 14 of the children had a positive assay result-i.e., a significant increase in cell death associated with phenytoin metabolites. Each child with a positive result had one parent whose cells also were positive. A positive in vitro challenge was highly correlated with major birth defects, including congenital heart disease, cleft lip/palate, microcephaly, and major genitourinary, eye, and limb defects. There was no difference between children with positive and negative results in the number or distribution of minor birth defects, including stigmata of the fetal hydantoin syndrome. Although many factors contribute to the outcome of pregnancies in epileptic women treated with phenytoin, a genetic defect in arene oxide detoxification seems to increase the risk of the baby having major birth defects. 